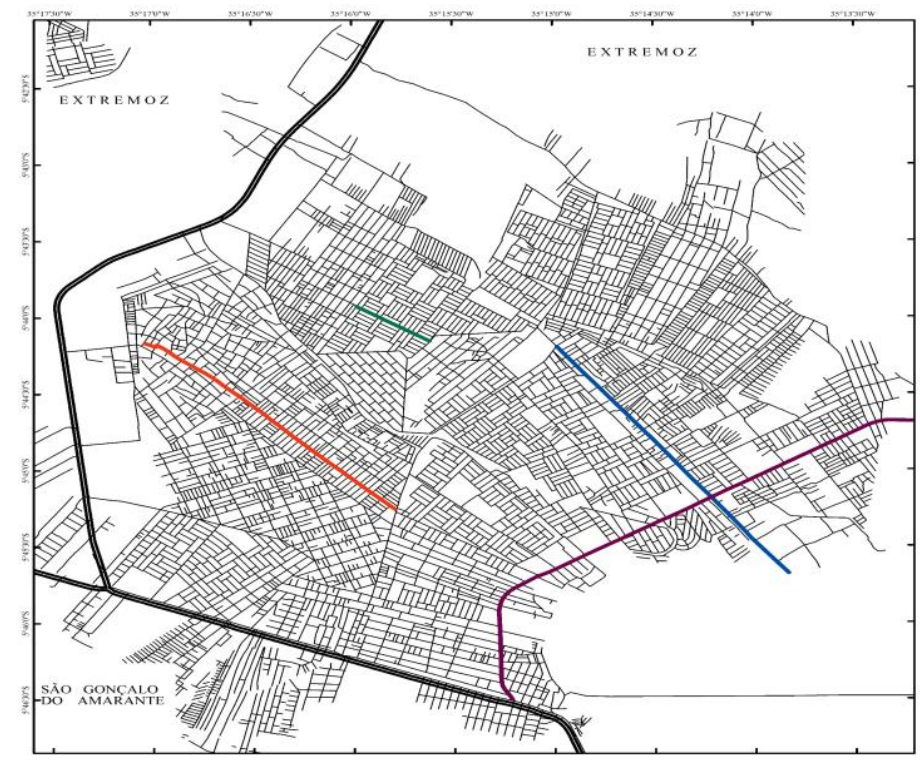

\title{
Atividade comercial na Zona Norte de Natal: análise das ruas de comércio tradicional
}

The commercial activity at Natal"s Zona Norte: an analysis of the traditional shopping streets

\author{
Rita de Cássia da Conceição Gomes ${ }^{1}$ \\ Soneide Moura da Costa ${ }^{2}$ \\ Joabio Alekson Cortez Costa ${ }^{3}$
}

Resumo: O artigo objetiva analisar as ruas de comércio nas ruas Pompéia, Chegança e Boa Sorte, localizadas na Zona Norte de Natal, Rio Grande do Norte (RN), enquanto constituintes de um novo momento na dinâmica urbana da cidade do Natal, e seu desdobramento na Zona Norte. Os procedimentos metodológicos compreenderam levantamento bibliográfico e pesquisa de campo no objeto em questão. As ruas de comércio em tela representam um padrão de atividade comercial de segmento popular classificado como comércio tradicional. A atividade comercial nesses espaços dinamiza a economia urbana da Zona Norte, e permite a reprodução do capital, ao mesmo tempo em que incorpora elementos do cotidiano local.

Palavras-chave: Comércio tradicional, ruas de comércio, Zona Norte (Natal/RN)

Abstract: The article discusses the commerce streets Pompéia, Chegança and Boa Sorte located in the North Zone of Natal-RN as constituents of a new moment in urban dynamics of Natal and their deployment in the North Zone. The methodological procedures included reading texts and field research on the subject matter. The shopping streets represent a pattern of commercial activity popular segment classified as traditional trade. The commercial activity in these areas increases the Urban of Zona Norte economyand lets the reproduction of capital.It also incorporates the local daily elements.

Keywords: Traditional Commerce, streets of commerce, Zona Norte (Natal/RN)

${ }^{1}$ Professora Dr ${ }^{\mathrm{a}}$ do Departamento de Geografia da UFRN. E-mail: ricassiacg@gmail.com. Endereço: Caixa Postal 1524 - Campus Universitário Lagoa Nova, Centro de Ciências Humanas, Letras e Artes, CEP 59078-970, Natal/RN - Brasil.

${ }^{2}$ Mestranda pelo Programa de pós-graduação em Geografia da UFRN. E-mail: soneidemoura@hotmail.com. Endereço: Caixa Postal 1524 - Campus Universitário Lagoa Nova, Centro de Ciências Humanas, Letras e Artes, CEP 59078-970, Natal/RN - Brasil.

${ }^{3}$ Graduando em Geografia pela UFRN. E-mail: joabioalek@ hotmail.com. Endereço: Caixa Postal 1524 Campus Universitário Lagoa Nova, Centro de Ciências Humanas, Letras e Artes, CEP 59078-970, Natal/RN - Brasil. 


\section{Introdução}

Analisando a dinâmica urbana de Natal/RN, constata-se uma expansão das atividades terciárias na Zona Norte, decorrente da "onda" de investimentos para ela direcionados, sobretudo, a partir de meados da década de 1990. Até a década de 1970, a Zona Norte se constituía num espaço cuja função era de habitação, associada às políticas sociais, sendo um espaço da cidade com expressivo número de habitantes.

Tendo em vista o aumento do seu contingente populacional, essa expressiva população, associada à política de expansão do turismo rumo às praias do litoral localizadas ao norte de Natal, propiciada, principalmente pelo Programa de Desenvolvimento do Turismo no Nordeste (PRODETUR/NE), fizeram emergir a necessidade de implementação de equipamentos sociais - escolas, praças, hospitais, dentre outros, os quais contribuíram para uma dinamização da economia urbana, destacando então as atividades comerciais.

Desse modo, a partir dos anos 1980, e principalmente em 1990, o setor terciário ganhou pujança no referido espaço mediante a chegada de investimentos do capital privado ligado ao varejo moderno. Além disso, houve uma expansão do comércio tradicional.

Os incentivos públicos e privados voltados à Zona Norte desencadearam o surgimento de novos espaços comerciais no contexto de Natal, segundo a lógica de ocupação das vias expressas de circulação. É o caso das Avenidas Tomas Landim, Doutor João Medeiros Filho e das Fronteiras, que são, na realidade, eixos articuladores da Zona Norte a outras áreas da cidade. Nessas vias, encontram-se equipamentos comerciais do varejo moderno e de serviços, sendo o Partage Norte Shopping Natal, Supermercado Nordestão, Distribuidora Sacolão, Carrefour; além de equipamentos sociais, escolas privadas, serviços público-administrativos como a Central do Cidadão, serviços de saúde em geral como o hospital Centro Médico Zona Norte, e especializados, incluindo o Instituto do Rim.

Nas proximidades dessas avenidas, firmou-se e se desenvolveu o comércio tradicional, com lojas de pequeno porte, pouco ou nada especializadas, de atendimento marcado pelas relações de proximidade com o cliente, dando uma função nova às ruas que antes eram apenas de habitação, isto é, a função comercial; daí porque denominadas ruas comerciais, as quais mesmo não se configurando como grandes corredores de passagem, conseguem desvendar a lógica própria de reprodução socioespacial. 
Fernandes (2000), ao analisar a realidade portuguesa, compreende o comércio tradicional como uma classe da atividade comercial que se contrapõe às novas formas comerciais (centros comerciais, hipermercados, supermercados, grandes superfícies especializadas etc.) no contexto da "Revolução Comercial", caracterizada em linhas gerais pela introdução de novas formas de organização e gestão das atividades no interior dos estabelecimentos comerciais, introdução de novas tecnologias, novas formas de venda e a implantação do autosserviço.

Para Fernandes (2000, p.10) "o aparelho comercial tradicional, é formado por pequenos estabelecimentos, generalistas ou especializados na oferta de um número reduzido de produtos afectos a ramos de actividade específicos" e são geridos essencialmente por pequenos empresários, comerciantes independentes e pequenas sociedades por quota.

Nesse sentido, concordamos com o ponto de vista de Salgueiro (1996, p. 124), sobre a importância dos tradicionais pequenos comércios presentes nos bairros da cidade: “As grandes superfícies nunca poderão anular completamente o pequeno comércio, pois há muita coisa que será sempre preciso adquirir ao pé da porta e até em horas menos normais". De acordo ainda com a referida autora (Ibidem, p. 4),

É a forma tradicional do comércio, caracterizada pela presença de empresas de dimensões relativamente modestas, e continua largamente maioritária em todos os países, embora a sua quota no volume de transações tenha vindo a reduzir-se e deva continuar a diminuir. O processo de concentração será o motor das formas seguintes.

O comércio tradicional é também comércio de proximidade, este mais associado às práticas de negócio, de gestão e de atividades diárias menos modernas, contudo, não obsoletas. Para Barreta (2012, p. 71),

O comércio de proximidade terá de apostar nos clientes e não tanto nos consumidores, isto é, o seu negócio deve ser trabalhado em prol do clientepessoa (único e conhecido) e não tanto do cliente-consumidor (mais um e, teoricamente, menos conhecido).

O tratamento personalizado com o cliente; a organização simples do estabelecimento; o pequeno, mas significativo, estoque de mercadorias; e a quase completa ausência de publicidade constituem algumas características comuns às atividades de comércio de proximidade. Assim,

O comércio de proximidade (...) remete para a proximidade para com o cliente, traduzida no conhecimento das suas necessidades e desejos, na relação próxima estabelecida entre as partes, extravasando a mera 
proximidade física. (...) $\mathrm{O}$ conceito de comércio de proximidade retrata o comércio que está próximo da sua procura, não só fisicamente, mas também, e principalmente, social, cultural, patrimonial e ... comercialmente (Barreta, 2012, p.14).

Nesta perspectiva, Santos (1997) afirma que o papel da proximidade é extremamente importante nas relações com a população local e para no funcionamento dos comércios dos bairros. A proximidade se refere à totalidade das relações, não apenas no sentido econômico, mas à proximidade física entre as pessoas num mesmo conjunto de pontos contínuos, vivendo com a mesma intensidade suas interrelações, criando laços profundos de identidade, de solidariedade. De acordo com Salgueiro (1996, p. 124), “Os pontos fortes do pequeno comércio, em relação às grandes superfícies, são a proximidade aos consumidores e a qualidade do serviço prestado".

Esse quadro de referência nos instigou à realização desse trabalho que busca entender o processo de formação das ruas de comércio: Pompéia, Chegança e Boa Sorte, na Zona Norte de Natal. E este tipo configuração do comércio, sob a forma de ruas, é entendido como resultado da emergência das atividades terciárias e do próprio movimento de reprodução do capital, que repercute na dinamização do setor da economia popular urbana.

A discussão apresentada no texto em tela assume um caráter analítico, ancorado em leitura de textos, e principalmente, em pesquisa de campo, dado o fato de que, no $\mathrm{RN}$, os bancos de dados de atividades comerciais são ainda pouco valorizados, e possuem informações genéricas, fazendo com que eles constituam a principal fonte de referência para a execução do trabalho.

Embasaram a nossa compreensão teórica a leitura de trabalhos de Salgueiro (1996), Pintaudi (1999), Barreta (2012), Carlos (2001, 2007) e Fernandes (2000), que empreenderam uma discussão do aparelho comercial, considerando a relação tempo e espaço.

Para análise do desenvolvimento do comércio e suas implicações socioespaciais na Zona Norte de Natal, foi de fundamental importância trabalhos produzidos por geógrafas do RN, como Araújo (2004), que analisa a história da produção do espaço na Zona Norte, à luz do planejamento urbano e da gestão do território; e Paula (2010), que faz um estudo sobre a dinâmica comercial da atividade varejista moderna também na Zona Norte.

Entendendo que as ruas de comércio representam mais um elemento do cenário urbano, dada a configuração socioespacial por elas apresentada, e a sua 
representatividade na dinâmica comercial da Zona Norte, faz-se imperativo discutir, ainda que forma breve, o processo de expansão urbana de Natal, e seus consequentes rebatimentos no recorte espacial em questão.

\section{O contexto da expansão urbana de Natal e o surgimento das ruas de comércio na zona norte}

Segundo Costa (2000), a Capitania do Rio Grande (correspondente hoje ao território norte-riograndense) só foi efetivamente ocupada pelos colonizadores portugueses, praticamente, um século depois do início da colonização. A construção da Fortaleza dos Reis Magos, em 1598, e a fundação de Natal, um ano depois, são apontadas pelo autor como marcos da sua ocupação inicial.

Do início do século XVI, até meados do século XIX, a capital potiguar apresentou um ritmo lento de crescimento. No entanto, com o desenvolvimento da cultura algodoeira no interior da Província do RN, e a instalação do Cais Tavares de Lira, em 1869, no bairro da Ribeira, a cidade passou a apresentar uma dinâmica que se expressou espacialmente na constituição de novos bairros: Cidade Alta e Rocas. Até então, a Ribeira era o único bairro existente.

Ao longo da segunda metade do século XIX, a cidade foi contemplada com a instalação do sistema de iluminação pública e abastecimento de água, sobretudo, nas áreas ocupadas pelas classes altas da população (QUEIROZ, 2010, p. 5). No início do referido século, a população era em torno de 16 mil habitantes.

Em 1929, em virtude do lançamento do plano urbanístico pelo prefeito Omar O’Grady, a cidade passou por uma profunda transformação no que tange à sua morfologia (COSTA, 2000). Contudo, foi só a partir da II Segunda Guerra Mundial que Natal apresentou um acelerado processo de urbanização, fomentado pela implantação da Base Aérea Norte-americana, em 1940; da Base Naval; da Policlínica do Alecrim, em 1941; e do asfaltamento da estrada que ligava Natal a Parnamirim, correspondente hoje às Avenidas Hermes da Fonseca, Senador Salgador Filho e BR 101.

O grande incremento populacional na cidade, originado pela vinda de migrantes do interior, refugiados da seca de 1942 e das regiões produtoras de algodão - economia que a essa a altura entrava em processo de decadência, por motivos diversos, não cabendo aqui explicitar - acentuou o processo de expansão da área urbana e a formação de novos bairros (QUEIROZ, 2010). 
Na década de 1950, a cidade recebeu investimentos voltados ao setor de habitação, para suprir a demanda crescente, em virtude do aumento populacional; e também voltados à infraestrutura urbana. Nesse contexto, tiveram fundamental importância ações da Superintendência de Desenvolvimento do Nordeste (SUDENE), criada em 1959, cujo intuito principal era reduzir as desigualdades regionais a partir do estímulo ao crescimento econômico, sendo o desenvolvimento industrial o foco principal, como bem coloca Araújo (2004).

Nos anos 1970, período da Ditadura Militar, a criação do Banco Nacional de Habitação (BNH) impulsionou a política habitacional empreendida pelo Estado brasileiro, e Natal canalizou boa parte dos recursos destinados ao RN, sendo a Zona Norte bastante contemplada com essa política. Costa (2000) esclarece que a edificação de conjuntos habitacionais voltados para as classes de alta renda ficou sob incumbência do Instituto de Orientação às Cooperativas Habitacionais do Rio Grande do Norte (INOCOOP-RN), sendo a Caixa Econômica Federal (CEF) o principal financiador dessas obras.

O governo estadual, no seu intento, mediante o Plano Habitacional Popular, criou a Companhia de Habitação Popular do Rio Grande do Norte (COHAB-RN), cujo objetivo era a construção de casas para as classes menos abastadas, e financiadas pelo Banco Nacional de Habitação (BNH). A partir daí começou a ser esboçado um padrão de desigualdade urbana subsistente até os dias atuais: a Zona Sul foi privilegiada pela implantação de condomínios acessíveis apenas às camadas média e alta da população, e como consequência os investimentos em infraestruturas privilegiaram esse espaço da cidade; o contrário se sucedeu na Zona Norte, que até início dos anos 1990 era basicamente um "espaço dormitório".

Exerceu importância crucial no processo de crescimento urbano de Natal também a expansão do setor industrial. A criação do Parque Têxtil Integrado e do Distrito Industrial no seu entorno, nos municípios de São Gonçalo do Amarante e Extremoz, expandiu o mercado de emprego local e atraiu um significativo contingente de pessoas para a cidade, cuja parcela importante se concentrou na Zona Norte.

Outros fatores como a abertura de novas avenidas, a ampliação dos sistemas de saneamento básico e abastecimento de água, a construção de escolas e estabelecimentos de saúde, a inauguração do campus central da Universidade Federal do Rio Grande do 
Norte e a emergência do turismo, sobretudo, no início dos anos $1980^{4}$, favoreceram o processo de urbanização e reforçaram o papel de centralidade da capital potiguar, ao fomentar a ampliação e a diversificação do setor terciário local.

A partir dos anos 1970, e mais expressivamente em 1980, o setor terciário da Natal começou a se descentralizar, dirigindo-se para novas áreas, acompanhando o próprio movimento de concentração da população e de expansão da cidade. Os bairros tradicionalmente comerciais, como Alecrim, Ribeira e Cidade Alta, mantiveram-se, embora as atividades comerciais tenham passado por mudanças significativas, seja no formato dos estabelecimentos, seja no tipo de comércio.

A constituição das ruas tinha passado por mudanças expressivas, mas novos espaços também foram se constituindo, como é ó caso das ruas comerciais na Zona Norte de $\mathrm{Natal}^{5}$, as quais se inserem nesse processo de descentralização. Até então, a região correspondente hoje à Zona Norte de Natal era composta principalmente por chácaras, sítios, salinas, e um número reduzido de casas; a atividade agrícola preponderava.

A partir da década de 1960, com a construção da ponte Costa e Silva, popularmente conhecida como uma das "Pontes de Igapó", a Zona Norte passou a receber um contingente considerável de pessoas que ali buscavam construir suas casas, tendo em vista os baixos preços do solo em relação às demais zonas da cidade.

O mercado imobiliário voltado para o atendimento das classes menos abastadas visualizou nessa nova área de expansão da cidade uma ótima oportunidade de reprodução; e, assim, a Zona Norte começou a crescer. A implantação do Distrito Industrial de Natal e do Parque Têxtil Integrado, somada à intensa dinâmica imobiliária, é apontada por Paula (2010) como alguns dos fatores determinantes para o processo de urbanização da Zona Norte.

Segundo Araújo (2004), após a segunda metade da década de 1990, uma nova dinâmica socioespacial teve início no espaço da Zona Norte, constituindo-se, antes de mais nada, como uma expressão do movimento de acumulação do capital, para o qual ela apresentar-se-ia como um lugar adequado para a sua reprodução.

\footnotetext{
${ }^{4}$ Furtado (2005) coloca que nos anos 1980 Natal apresentou um "boom" da atividade turística, firmandose como um dos principais destinos turísticos do Nordeste.

${ }^{5}$ Natal se encontra dividida em quatro regiões administrativas: Região Administrativa Norte, Região Administrativa Sul, Região Administrativa Oeste e Região Administrativa Leste.

${ }^{6}$ A ponte Costa e Silva foi construída ao lado da antiga Ponte de Igapó, inaugurada em 1916, e que hoje se encontra em desuso. A ponte atravessa o rio Potengi, que corta a Cidade do Natal, articulando a Zona Norte às demais Zonas.
} 
Essa dinâmica foi definida pela expansão das atividades terciárias - comércio e serviços - e teve como motor principal não somente o Estado, que até então vinha promovendo o desenvolvimento desse espaço mediante a implantação de conjuntos habitacionais e o estímulo à indústria, mas também o capital.

A expansão do mencionado setor assume duas orientações: uma expressa pela expansão do varejo moderno; e a outra, pelo surgimento de um comércio popular. No que diz respeito ao varejo moderno, ressaltamos a instalação de shoppings, supermercados e hipermercados, lojas especializadas, megalojas e lojas de departamento, como resultantes da expansão desse comércio existente na Zona Sul e no centro de Natal. Já o comércio popular pode ser compreendido como uma decorrência da demanda da população de baixa renda, mas principalmente, como uma alternativa e estratégia de sobrevivência da população que não conseguia se inserir no mercado de trabalho.

Esse desdobramento da atividade comercial visualizado já no início dos anos 1980 e reforçado na década seguinte foi uma das formas de o grande capital aproveitar o poder de compra do mercado consumidor ali presente, embora os rendimentos da maior parte da sua população estivessem na faixa de 2,92 salários mínimos em 2010.

Neste sentido, “A Zona Norte (...) tem se tornado um espaço privilegiado de expansão do capital, visto que o mesmo assume diversas formas, a fim de garantir, segundo o seu processo de produção desigual e combinado, a sua reprodução" (ARAÚJO, 2004, p. 243). O setor terciário ao se apropriar dos diferentes espaços também cria novas territorialidades, pois como esclarecem Gomes et al (2000, p. 74):

\footnotetext{
A espacialidade do terciário tem se expressado, ao longo do tempo, de forma bastante diferenciada, isto é, a cada momento de crescimento econômico, novas espacialidades vão surgindo e, por conseguinte, novas territorialidades vão se configurando, o que demonstra uma forte dinamicidade do setor.
}

Seguindo esse pressuposto, buscar-se-á na sequência compreender a formação e dinâmica das ruas de comércio Pompéia, Chegança e Boa Sorte, localizadas na Zona Norte, enquanto expressões concretas do processo analisado.

\section{Um olhar sobre a rua: abordagem teórica}

Os estudos sobre comércio, e em especial, sobre ruas de comércio, revelam a necessidade de entender a constante reinvenção desta atividade no espaço urbano, pois conforme Pintaudi (1999, p. 143-144), “A atividade comercial pertence à essência do urbano e seu aprofundamento nos permite um melhor conhecimento desse espaço e da 
vida da cidade". Sendo assim, é pertinente que antes de enveredarmos na compreensão teórica do significado e conteúdo das ruas de comércio, refletirmos um pouco sobre a compreensão conceitual e significado da rua.

Diversos são os conceitos sobre rua. Na literatura ou no senso comum, a rua compartilha do mesmo sentido: lugar de encontro seja de pessoas, informação ou mercadorias.

Conferindo-lhe uma abordagem filosófica, Lefebvre (1999, p. 29) entende que a rua

Não se trata simplesmente de um lugar de passagem e circulação (...) É o lugar do encontro (topia) do encontro, sem o qual não existem outros encontros possíveis nos lugares determinados (cafés, teatros, salas diversas). Esses lugares privilegiados animam a rua e são favorecidos por sua animação, ou então não existem. Nela efetua-se o movimento, a mistura, sem os quais não há vida urbana, mas separação, segregação estipulada e imobilizada.

No âmbito da geografia, a rua é entendida este geralmente como lugar de circulação e também lugar da moradia. Do ponto de vista do cotidiano, as ruas constituem elemento importante no entendimento de relações sociais que nela se desenvolvem. Elas refletem o vivido pela sociedade que ali estabeleceu as suas práticas sociais num determinado tempo e espaço.

As mudanças na temporalidade do uso da rua também implicam mudanças na dinâmica social do lugar. Assim,

A rua não é só o lugar do espetáculo urbano; trajetos se recobrem de sentido. Transformam-se em testemunho coletivo das formas de apropriação. A rua vai ganhando sentido, ritmo da vida cotidiana, do tempo que determina o uso pelos estratos da sociedade (CARLOS, 2001, p. 56).

A rua pode ser pensada como o lugar onde se estabelecem relações das mais variadas esferas. É o lugar da experiência, onde os conflitos sociais se instalam. Através dela, pode-se fazer uma leitura do cotidiano da sociedade com suas dissonâncias, rotina, estratégia de sobrevivência. A rua "é o lugar onde o indivíduo e o coletivo se mesclam em um jogo de impressões e significados múltiplos, reveladores do conteúdo da vida na grande cidade". (CARLOS, 2001, p. 56). A rua também "aparece como lugar de mercado e da troca, como lugar da festa, do ato religioso, da identificação dos encontros e reencontros" (CARLOS, 2001, p. 60). 
No decurso do tempo, a rua ganha forma mediada pela ação, e assim, vai se transformando também como resposta da metamorfose da sociedade urbana, impondose como modo de vida. De acordo com CARLOS (2007, p. 51),

Finalmente na rua se tornam claras as formas de apropriação do lugar e da cidade, e é aí que afloram as diferenças e as contradições que permeiam a vida cotidiana, bem como as tendências de homogeneização e normatização impostas pelas estratégias do poder que subordina o social. A cidade é reproduzida a partir da articulação de áreas diferenciadas com temporalidades diferenciais que se produzem, fundamentalmente, da constituição de uma forma de apropriação para uso que envolve especialidades que dizem respeito à cultura, aos hábitos costumes, etc..., que produzem singularidades espaciais que criam lugares na cidade das quais a rua aparece como elemento importante de análise.

Nesse sentido, o complexo traçado das ruas se encontra imbricado em uma rede de idas e vindas, mas, antes de tudo, revela um modo de apropriação para a vida, frequentações acabando por sinalizar o espaço da liberdade (Ibidem, p. 61).

É dessa forma, ou seja, por meio das idas e vindas e da apropriação que as ruas, enquanto espaços de liberdade apresentam formas e conteúdos diversos, assumindo também funções diversas. Assim são as ruas de comércio.

\section{As ruas de comércio: a captura do lugar pelo olhar}

A rua não é só o lugar do espetáculo urbano; trajetos se recobrem de sentido. (CARLOS, 2001, p. 56).

As ruas de comércio assumem importância significativa no processo de produção do espaço urbano, graças às múltiplas relações sociais a elas intrínsecas. Desse modo, entender a dinâmica comercial que ocorre nas ruas Pompéia, Chegança e Boa Sorte (representadas na figura 01) é entender formas e processos que desencadeiam a produção do espaço urbano de Natal; e, de forma peculiar da Zona Norte. Mais que espaços de encontro, essas ruas são, principalmente, expressões concretas da materialização de padrões locacionais da atividade comercial na cidade. 


\section{Figura 01: Ruas de Comércio da Zona Norte - Natal/RN}

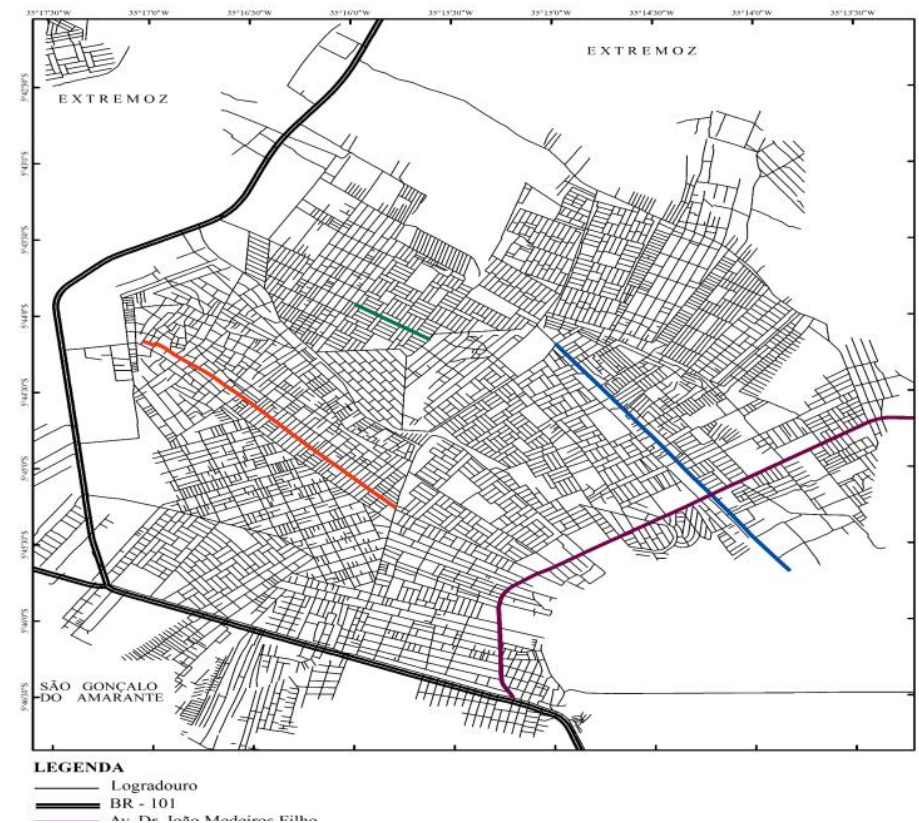

Sistema de Projeção de Coordenadas Datum SIRGAS 2000 Malha Municipal do IBGE/2010 Fonte: Secretaria Municipal de Meio Ambiente e Urbanismo de Natal-RN Elaboração cartográfica: Joabio Costa/2015.

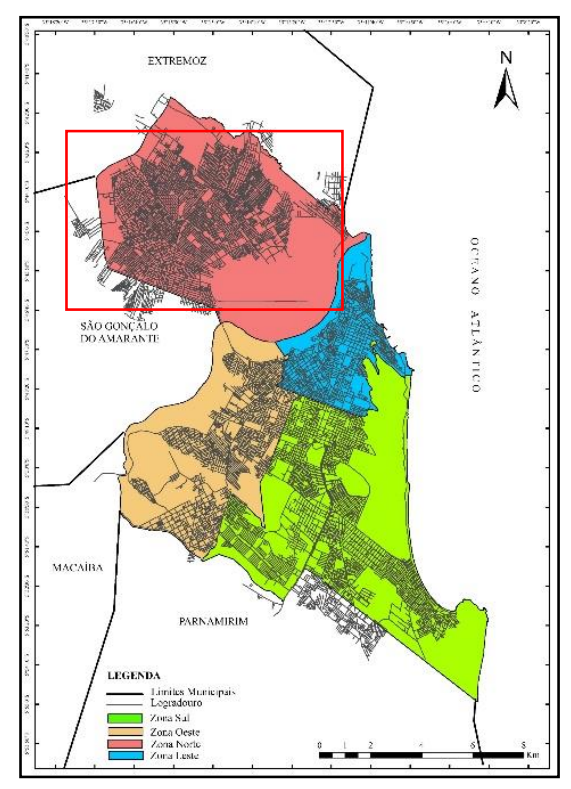

As ruas de comércio Pompéia, Boa Sorte e Chegança estão localizadas na Zona Norte nos bairros Pajuçara, Nossa Senhora da Apresentação e Lagoa Azul respectivamente. A função inicial destas ruas era voltada fundamentalmente para a habitação e com a expansão urbana da cidade e consequentemente a expansão do terciário, as ruas passaram a ter função predominantemente comercial. Em decorrência dessa realidade, a primeira questão a ser evidenciada diz respeito à não regularização dos estabelecimentos. Segundo informações obtidas junto à Secretaria Municipal de Meio Ambiente e Urbanismo (SEMURB), a grande maioria dos estabelecimentos não é regularizada pelo órgão responsável, não possuindo licença do uso territorial, porque não obedecem à disciplina urbanística (emissão de barulho, fumaça, vagas de estacionamento).

Entretanto, juridicamente, os estabelecimentos obtêm a licença de funcionamento, a qual é concedida pelo Serviço Brasileiro de Apoio às Micro e Pequenas Empresas (SEBRAE), que classifica o estabelecimento no núcleo de empreendedor individual. Neste contexto, o comerciante passa a integrar o grupo de 
microempreendedor individual, com um teto salarial de 30.000 reais anuais ou 2.500 mensais.

Os valores anunciados são expressões evidentes de uma atividade comercial que tem como principal característica o caráter familiar, sendo, portanto, um comércio que se reproduz em bases tradicionais; ou seja, apresenta formatos, composição e lógicas de reprodução que se distanciam de um comércio moderno.

Porém, o fato desse comércio ser do tipo tradicional, não significa que o mesmo se encontre fora do circuito de produção capitalista em sua totalidade. Muito pelo contrário, há uma reprodução que contribui de maneira significativa para a reprodução do capital. Sendo assim, esse comércio também é um fator importante para a produção do espaço urbano.

Desse modo, ainda que prevaleçam os empreendimentos comerciais que disponibilizam ao consumidor mercadorias de baixo custo, como vestuário, em sua maioria, oriundo do polo industrial têxtil do agreste pernambucano, podemos encontrar nessas ruas, lojas especializadas em venda de eletrônicos, clínicas odontológicas, restaurantes, lanchonetes, casas lotéricas, farmácias, padarias, dentre outros.

Fazendo uma leitura individual de cada rua estudada temos a seguinte realidade. No que concerne às características propriamente ditas das ruas fazemos as seguintes considerações. A rua de comércio da Pompéia (figura 02), apresenta uma tipologia variada ao longo da sua configuração, no que diz respeito ao tipo de comércio instalado.

Figura 02 - Rua de comércio Pompéia

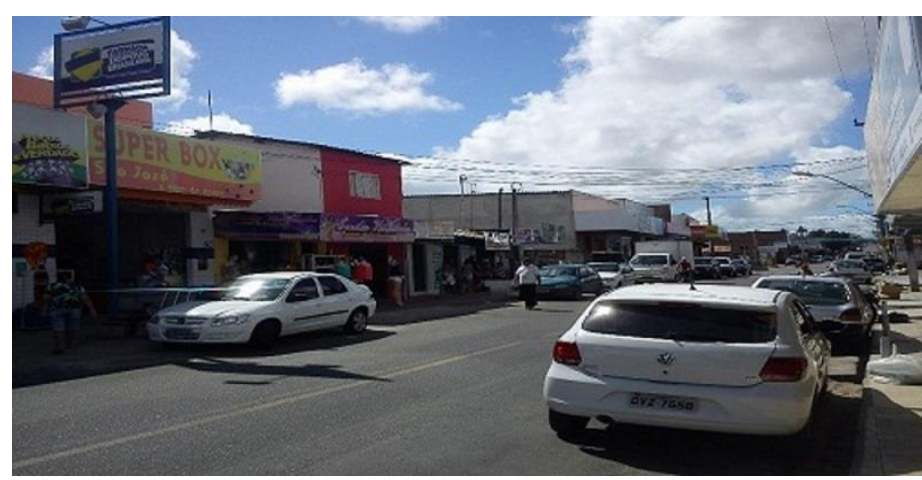

Fonte: Acervo dos autores, 2015.

A Pompéia apresenta os primeiros elementos que a caracterizam como rua de comércio, já na porção perpendicular à Avenida Doutor João Medeiros Filho, uma das principais artérias da atividade comercial da Zona Norte. Da Avenida João Medeiros 
Filhos às proximidades da rua dos "Itororó", a Pompéia caracteriza-se substancialmente pela oferta de serviços, como consertos de eletroeletrônicos e eletrodomésticos, borracharia, restaurante e salão de beleza.

No trecho compreendido entre as ruas "Itororó" e "A Salomé", dispostas perpendicularmente à Pompéia, tem a presença de lojas especializadas na comercialização de um determinado segmento de produto, concentradas em uma porção da extensão da rua; destacam-se as lojas de vestuário, cujas mercadorias são de baixo preço, e reúnem características semelhantes ao tipo de material de fabricação, às faixas de preços e às estampas que, na sua maioria, são de cores vibrantes (figura 03).

Neste recorte, o fluxo de pessoas é mais dinâmico em relação ao restante da rua, uma vez que próximo às lojas de confecções também verificamos a oferta de serviços, como casas lotéricas, clínicas odontológicas, salão de beleza, lanchonete etc.

Entre as ruas "A Salomé" e a "Travessa Hortência", evidencia-se a localização alternada de farmácias populares e clínicas odontológicas, ambas de caráter popular.

\section{Figura 03 - Porção da rua de comércio Pompéia com predominância de lojas de confecções}

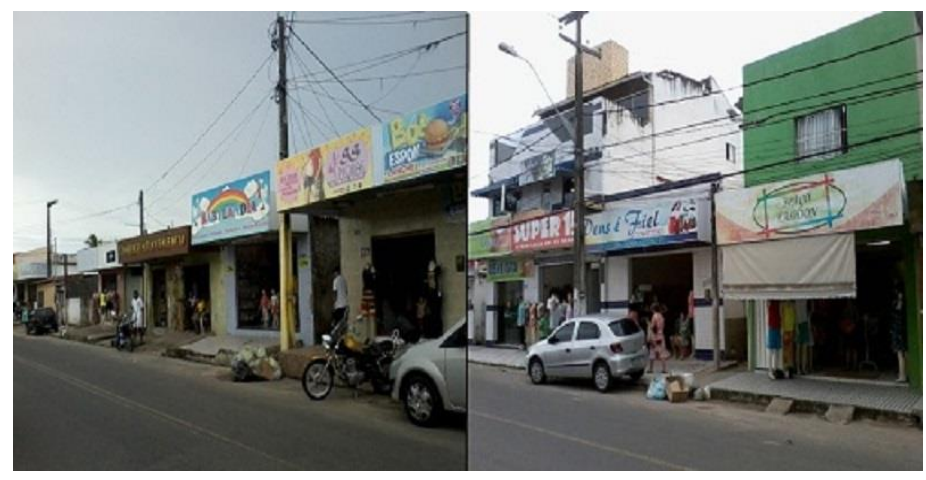

Fonte: Acervo dos autores, 2015.

Quanto à análise dos aspectos da rua de comércio Boa Sorte (figura 04), esta apresenta uma tipologia de lojas variadas, possui estabelecimentos comerciais de pequeno porte, e está voltada para atender à população de classe menos favorecida. 
Figura 04- Rua de comércio Boa Sorte

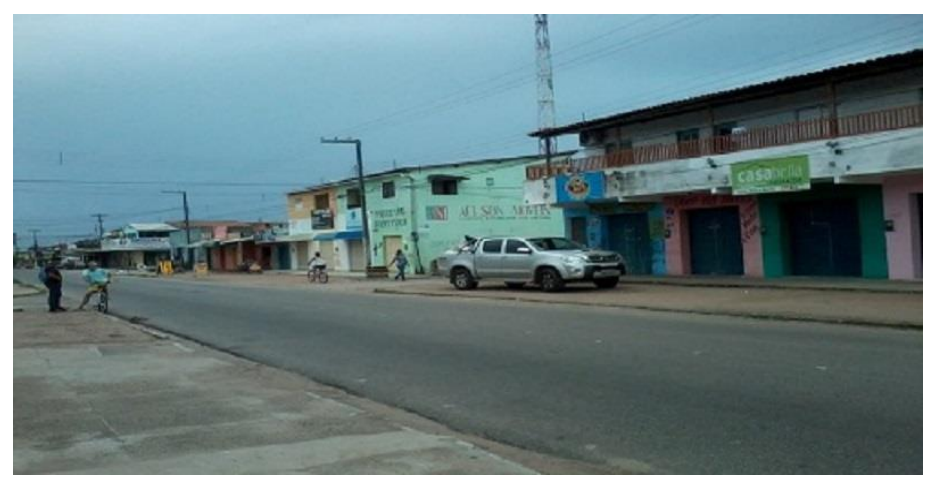

Fonte: Acervo dos autores, 2015.

Nesta rua, percebemos uma característica não observada nas demais analisadas: em quase toda a sua extensão, podemos perceber que os estabelecimentos comerciais são quase todos geminados com as residências (em alguns casos há uma adaptação, e a casa está localizada na parte de cima do estabelecimento, conforme a figura 05), o que sugere a hipótese de que a rua servia eminentemente para a função habitacional, e passou por um processo de adaptação no uso para também fornecer espaço à formação do comércio.

\section{Figura 05- Modelo de constituição dos estabelecimentos comerciais}

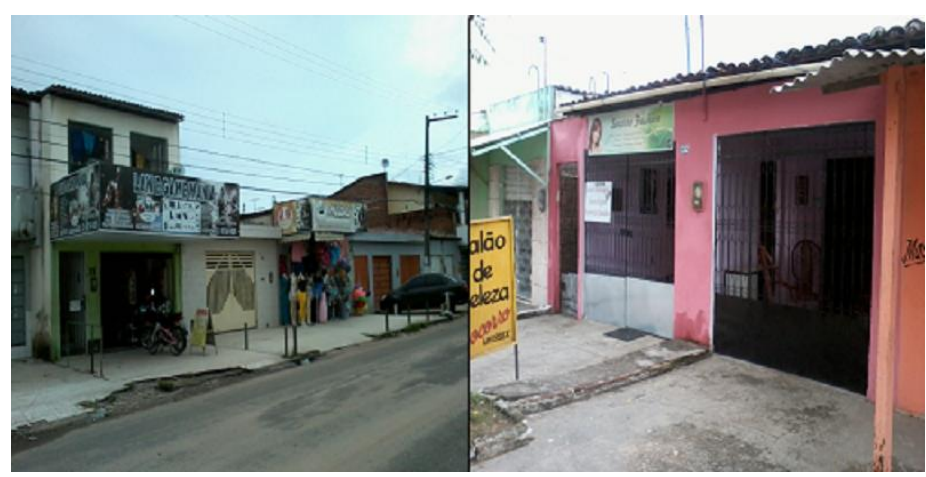

Fonte: Acervo dos autores, 2015.

Conforme evidenciado nas figuras, as lojas são conjugadas com a residência do proprietário, apontando para o caráter de gestão familiar desses estabelecimentos (Figura 05). No entanto, é precisar chamar a atenção para o fato de que em alguns trechos da rua já não existem casas, apenas estabelecimentos comerciais (figura 06). 


\section{Figura 06 - Rua intercalada com estabelecimentos, sem e com associação de} moradia

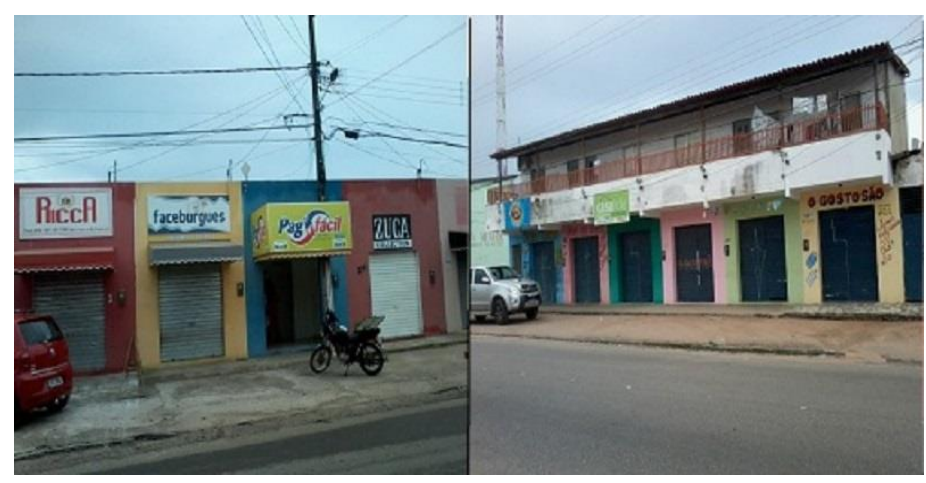

Fonte: Acervo dos autores, 2015.

Um olhar mais atento sobre o trecho da rua Boa Sorte, representado na figura anterior, revela dois aspectos bastante instigantes: do lado esquerdo observamos um conjunto de lojas desvinculadas de qualquer traço de moradia; do outro, percebemos a presença de várias moradias na parte superior dos estabelecimentos. Tal observação instiga o seguinte questionamento: estaria a Rua Boa Sorte passando por um processo de mudança no seu uso para tornar-se uma rua para fins estritamente comerciais, ou esta rua de comércio está se desenvolvendo em concomitância com a habitação?

Durante a pesquisa de campo, foi observado que as lojas de todas as ruas em análise encerram temporariamente suas atividades no horário do almoço, por volta do meio dia, retornado às suas atividades normais às 14 horas. Em virtude dessa rotina, no intervalo correspondente ao horário de fechamento das lojas, as ruas ficam praticamente desertas, pois o fluxo de pessoas que as animam e lhe dão vida é significativamente reduzido. Quem passa nesse horário e está acostumado com a dinamicidade das ruas no horário comercial depara-se com uma sensação de vazio.

\section{Figura 07 - Rua de comércio Chegança}

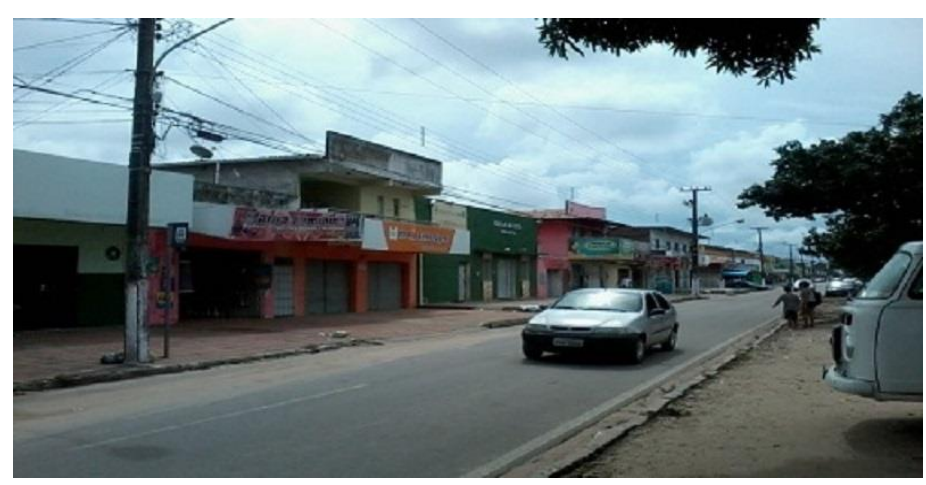

Fonte: Acervo dos autores, 2015. 
O comércio da referida rua está presente em toda a sua extensão, e apresenta perfil de lojas bastante variado, marcado pela presença de estabelecimentos que vão desde pequenas lan houses até lojas de móveis e farmácias, cuja área física é maior, se comparada às dos demais estabelecimentos.

Desta forma, na rua de comércio da Chegança existem formas modernas e tradicionais de comércio, conforme a figura abaixo (figura 08), na qual existem dois supermercados, porém, um deles, o da esquerda, mantém uma fachada bastante atrativa, com horário de atendimento estendido durante o almoço; enquanto ao seu lado, encontra-se um supermercado de pequeno porte, de aparência física deteriorada.

Importa fazer uma ressalva: na Rua da Chegança, mesmo nos estabelecimentos cujas formas físicas e a organização interna incorporam elementos vistos como modernos, a mercadoria comercializada nesta é compatível com o poder aquisitivo da população do bairro Lagoa Azul.

\section{Figura 08 - Coexistências de estabelecimentos comerciais}

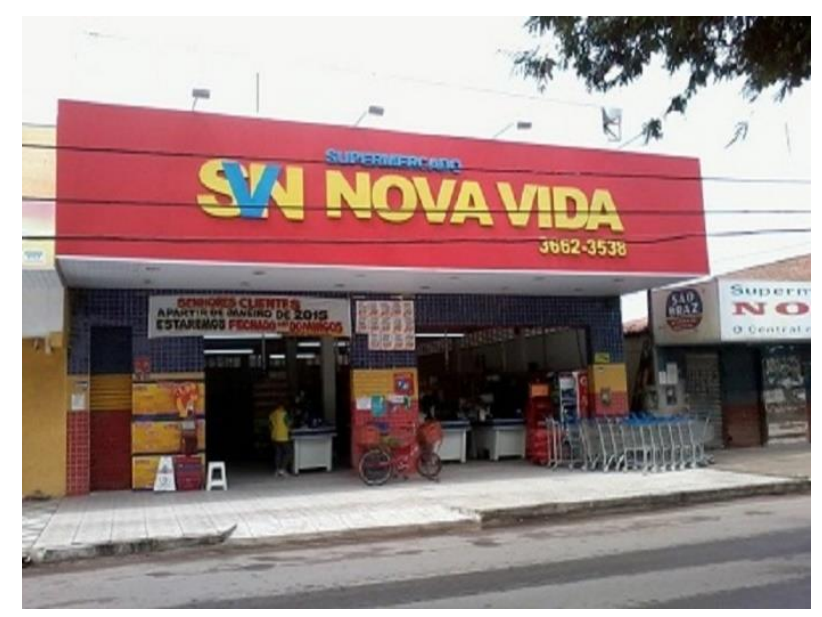

Fonte: Acervo dos autores, 2015.

É característica também a forma de exposição da mercadoria, principalmente quando se refere às lojas de confecções (figura 09). Na porção mais central da rua da Chegança vemos um aglomerado de lojas de confecções, nas quais, algumas mercadorias são apresentadas em manequins dispostos de forma desorganizada sem a aparente preocupação para a disposição ou combinação das mercadorias. Assim, ao invés de despertar a atenção do consumidor como pretende, os manequins acabam sendo subutilizados, e a mercadoria já não consegue se projetar de maneira cativante aos olhos de quem passa em frente à loja.

E apesar da aparente desorganização dos estabelecimentos no que se refere à disposição das suas mercadorias, concordamos que “A rua, série de vitrines, exposição 
de objetos à venda, mostra como a lógica da mercadoria é acompanhada de uma contemplação (passiva) que adquire o aspecto e a importância de uma estética e de uma ética" (Lefebvre, 1999, p. 31).

Figura 09- Concentração de lojas de confecções

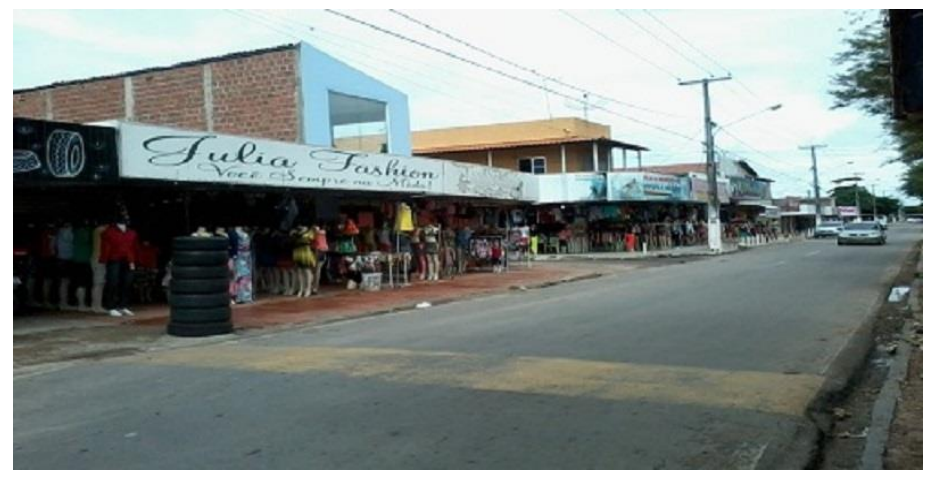

Fonte: Acervo dos autores, 2015.

As ruas de comércio Pompéia, Chegança e Boa Sorte enquadram-se na tipologia comércio tradicional. Nas palavras de Barreta (2012, p 13) o comércio tradicional "é formado por pequenos estabelecimentos, generalistas ou especializados na oferta de um número reduzido de produtos afetos a ramos de atividade específicos”.

\section{Considerações finais}

As características do comércio de proximidade, ou seja, aquele comércio que está próximo da realidade do cliente não só fisicamente, mas também social e econômico, são bem evidenciadas no contexto das ruas da Pompéia, Chegança e Boa Sorte. Durante a pesquisa de campo, observamos que muitos comerciantes locais mantêm relações bastante próximas com os consumidores. Ademais, percebemos que o espaço interior e a própria fachada da maioria dos estabelecimentos são simples, e não apresentam grandes inovações no que se refere à organização interna, à ambientação e ao tipo de material de fabricação dos móveis.

Essa situação deriva do fato de as atividades comerciais, ao longo dessas ruas, terem surgido basicamente para suprir as demandas da população residente nas proximidades. Logo, elas se adaptaram à capacidade de consumo desse grupo, e conquistaram a sua clientela.

Afora isso, muitos dos moradores que ali residiam, enxergando a possibilidade de obter rendimentos e garantir a própria reprodução familiar, investiram na criação do próprio negócio, e por já terem estabelecida uma rede de relações anterior com os que ali viviam, conseguiram conquistar clientes fidedignos. 
A reduzida capacidade de mobilidade da população, dadas as suas limitações financeiras, faz com que muitos busquem satisfazer suas necessidades mais imediatas de alimentação, saúde e vestuário nas proximidades, dirigindo-se apenas para outras áreas da cidade quando querem obter bens e serviços mais complexos ou que não sejam ofertados nos estabelecimentos dessas ruas. O comércio local é então beneficiado.

Como podemos observar, as atividades comerciais e de serviços que se desenvolvem nas ruas em análise são fruto de processos complexos, e estão inseridos no interior do próprio processo de expansão urbana de Natal e do movimento de reprodução do capital.

As ruas de comércio Pompéia, Chegança e Boa Sorte se reconfiguraram socioespacialmente, deixando de ser funcionalmente voltada apenas para a moradia, e passando a desenvolver o comércio tradicional, atraindo uma parcela da população natalense interessada no consumo menos burocrático e mais acessível, tanto no que concerne ao acesso quanto ao custo do consumo. Neste sentido, as ruas de comércio tornam-se espaços marcados por dinâmicas específicas atreladas à reprodução da vida, daí porque proprietários de determinadas residências fazem adaptações às suas moradias realocando-as para a porção interior ou superior do imóvel fazendo surgir novas possibilidades de renda mediante o aluguel de parte deste para o comércio. Daí se fazer presente comerciantes de outras áreas da cidade, muitos dos quais não residem na Zona Norte, mas que, em função do baixo valor do solo urbano e também do aluguel, fixaram estabelecimento comercial naquelas localidades.

Ainda refletindo a dinâmica das ruas, pode-se perceber a presença de consumidores de perfis diversos, tais como: jovens interessados nos artigos da moda recentemente apresentados na mídia e reproduzidos nas ruas de comércio, donas de casa e homens que buscam atender as suas necessidades de vestuário básico, mas que também acessam serviços de saúde, educação e de aquisição de gêneros alimentícios. Em resumo, as ruas de comércio são espaços que apresentam uma oferta de produtos comerciais e de serviços variados não se constituindo em ruas especializadas.

Portanto, o comércio da Pompéia, Chegança e Boa Sorte é de organização simples, com pequeno estoque de mercadorias, com gestão de predominância de emprego familiar, além da presença de pequenas lojas, mercadinhos, padarias, farmácia e outros, e se constitui num importante meio para o consumo por parte população.

Estas ruas se desenvolvem aceleradamente, procuram atender à demanda da população do bairro, da vizinhança; e, secundariamente, também de outras localidades 
da cidade, É um comércio que está próximo da realidade de consumo da população de baixa renda, ainda com o diferencial de privilegiar o cliente, e não somente $\mathrm{o}$ consumidor.

A formação dessas ruas, no entanto, não segue o padrão urbanístico definido no Plano Diretor da cidade. Deste modo, fica evidente o descaso do Estado para com a organização desses novos espaços de concentração das atividades terciárias, prejudicando assim as próprias condições ambientais e urbanas.

Por outro lado, a pesquisa apontou para a predominância de atividades sem a regulação jurídica de qualquer órgão público ou privado, o que de certo modo contribui para o avanço da informalidade e dos problemas que a ela são inerentes.

\section{Referências}

ARAÚJO, Josélia Carvalho de. Outra Leitura do "Outro Lado": o espaço da Zona Norte em questão. Dissertação (Mestrado) - Universidade Federal do Rio Grande do Norte. Centro de Ciências Humanas, Letras e Artes. Programa de Pós-graduação em Geografia. Natal, 2004.

BARRETA, J. Fazer acontecer a regeneração urbana: o comércio de proximidade. Disponível em: http://cidadanialxamb.tripod.com/CIP_Comercio_de_Proximidade.pdf. Acesso em: set. 2014

CARLOS, Ana Fani Alessandri. Espaço-tempo na metrópole: a fragmentação da vida cotidiana. Contexto, São Paulo, 2001.

. O lugar no/do mundo. Edição eletrônica. LABUR, São Paulo, 2007

COSTA, Ademir Araújo da. A verticalização e as transformações do espaço urbano de Natal-RN. (Tese de Doutorado). UFRJ. Instituto de Geociências. Programa de PósGRaduação em Geografia. Rio de Janeiro, 2000. 352f.

DINIZ, L.D.S. Pequeno comércio e crescimento urbano: as bodegas e a formação dos bairros populares campinenses. Universidade Federal de Campina Grande, Campina Grande, 2007.

FURTADO, Edna Maria. A onda do turismo na cidade do sol: a reconfiguração urbana de Natal. Tese (Doutorado). Natal: UFRN, CCHLA, Programa de PósGraduação em Ciências Sociais, 2005.

GOMES, Rita de Cássia da Conceição; SILVA, Anieres Barbosa da; SILVA, Valdenildo Pedro da. Dinâmica e espacialidade do setor terciário na Cidade do Natal (RN). Sociedade e Território. Natal, v.14, n.1, 2000.

LEFEBVRE, H. A revolução urbana. Belo Horizonte: UFMG, 1999.

PAULA, Joseara Lima de. A dinâmica territorial do comércio varejista moderno da zona norte de Natal/RN. Dissertação (Mestrado). Universidade Federal do Rio Grande do Norte. Centro de Ciências Humanas, Letras e Artes. Programa de Pós-graduação em Geografia. Natal, 2010. 
PINTAUDI, Silvana Maria. A cidade e as formas do comércio. IN CARLOS, Ana Fani Alessandri; DAMIANI, Amélia Luisa; OLIVEIRA, Ariovaldo Umbelino de, CONTI, José Bueno; ROSS, Jurandy Luciano Sanches, COLTRINARI, Lylian; PONTUSCA, Nídia Nacib, LENCIONI, Sandra, PINTAUDI, Silvana Maria (Orgs.). Novos caminhos da geografia, Contexto, São Paulo, 1999.

QUEIROZ, Thiago Augusto Nogueira de. A Produção do espaço urbano de Natal/RN: Algumas considerações sobre as políticas públicas. Observatorium: Revista Eletrônica de Geografia, Uberlândia, v. 2, n. 4, p.2-16, jul. 2010.

SALGUEIRO, Teresa Barata. Do comércio à distribuição: roteiro de uma mudança. Oeiras: Celta Editora, 1996.

SANTOS, Milton. A natureza do espaço: técnica e tempo, razão e emoção. 2 ed. São Paulo: Hucitec, 1997. 
Para citar essa obra:

GOMES, R. C. C., COSTA, S. M., COSTA, J. A. C. Atividade comercial na Zona Norte de Natal: análise das ruas de comércio tradicional. In: RUA [online]. $\mathrm{n}^{\circ}$. 21 . Volume 2, p. 283 - 284 - ISSN 1413-2109. Novembro/2015. Consultada no Portal Labeurb - Revista do Laboratório de Estudos Urbanos do Núcleo de Desenvolvimento da Criatividade.

http://www.labeurb.unicamp.br/rua/

Capa: Joabio Costa/2015

Laboratório de Estudos Urbanos - LABEURB

Núcleo de Desenvolvimento da Criatividade - NUDECRI

Universidade Estadual de Campinas - UNICAMP

http://www.labeurb.unicamp.br/

Endereço:

LABEURB - LABORATÓRIO DE ESTUDOS URBANOS

UNICAMP/COCEN / NUDECRI

CAIXA POSTAL 6166

Campinas/SP - Brasil

CEP 13083-892

Fone/ Fax: (19) 3521-7900

Contato: http://www.labeurb.unicamp.br/contato 